\title{
Medical management and the decline in mortality from coronary heart disease
}

\author{
ROBERT BEAGLEHOLE
}

\begin{abstract}
The contribution of resuscitation before admission to hospital, coronary care units, treatment with beta blockers after myocardial infarction, coronary artery bypass surgery, and the treatment of hypertension to the decline in mortality from coronary heart disease in Auckland between 1974 and 1981 was assessed by using data from several population based studies.

There were 126 fewer deaths from coronary heart disease in Auckland in 1981 than expected from the 1974 rates among people less than 70 years. The specific medical interventions probably accounted for about $51(40 \%)$ of the 126 fewer deaths. Local data indicate that resuscitation before admission to hospital was responsible for $20(16 \%)$ of the 126 fewer deaths. Projections based on local data and trials carried out overseas suggest that up to $15(12 \%)$ of the 126 fewer deaths were due to the treatment of hypertension. Coronary care units and the use of beta blockers after myocardial infarction were estimated to be responsible for six $(5 \%)$ and three $(2 \%)$ of the 126 fewer deaths, respectively. The impact of coronary surgery was especially difficult to determine in the absence of appropriate randomised controlled trial data. Estimates of its contribution ranged from seven to $23(5 \%$ to $18 \%$ ) of the 126 fewer deaths.
\end{abstract}

\section{Introduction}

Explanations for the continuing decline in mortality from coronary heart disease in the United States and several other countries remain

\footnotetext{
Department of Community Health and General Practice, School of Medicine, University of Auckland, Auckland, New Zealand

ROBERT BEAGLEHOLE, MD, FRACP, associate professor of epidemiology

Correspondence to: c/o Dr J McKinlay, Cambridge Research Center, American Institute for Research, Cambridge, Massachusetts 02138, USA.
}

elusive. Recent reviews have concluded that a combination of primary preventive measures and medical interventions have been important. ${ }^{1-4}$ There is a shortage of appropriate data from defined populations to measure the relative contributions to the decline. Goldman and Cook, ${ }^{1}$ following Stern, ${ }^{5}$ suggested that $40 \%$ of the decline in the United States between 1968 and 1976 was attributable to specific medical interventions.

Mortality from coronary heart disease declined in New Zealand by $20 \%$ in the 14 years from $1968,{ }^{6}$ and between 1974 and 1981 there was a $16 \%$ decline in the sudden death rate in Auckland. ${ }^{7}$ In this paper data from several population based studies were used to measure the likely contribution of medical management to the decline in mortality from coronary heart disease in Auckland for the period 1974-81.

The population of Auckland at the 1981 Census was 829000 , one quarter of the total New Zealand population; the age structure of the Auckland population is similar to that of the total New Zealand population. The following components of medical management were examined: resuscitation before admission to hospital; coronary care units; the use of beta blockers after myocardial infarction; coronary artery bypass surgery; and the pharmacological treatment of hypertension.

\section{Impact of decline in coronary heart disease}

National mortality data indicate that in 1981 there were 506 fewer deaths from coronary heart disease (International Classification of Diseases (9th revision) codes 410-14) in New Zealand for people aged less than 70 than expected from the 1974 rates; this is equivalent to 126 ( 100 men, 26 women) fewer deaths from coronary heart disease in this age group in the Auckland region. This estimate is supported by data from two coronary heart disease registers conducted in Auckland in 1974 and 1981 that found that in 1981 there were 95 fewer sudden deaths in Auckland in people aged less than 70 than expected from the 1974 sudden death rates. ${ }^{7}$ In New Zealand, as elsewhere, most deaths from coronary heart disease are sudden. ${ }^{8}$ 


\section{Effect of medical management on mortality}

The table shows the effects of the components of medical management described below on the observed decline in mortality from coronary heart disease in Auckland in 1981.

Effect of medical management on the observed decline in mortality from coronary heart disease in 1981

\begin{tabular}{lcc}
\hline & $\begin{array}{c}\text { Estimated No of } \\
\text { extra survivors }\end{array}$ & $\begin{array}{c}\text { Contribution to } \\
\text { observed decline } \\
(126 \text { extra survivors }) \\
(\%)\end{array}$ \\
\hline $\begin{array}{l}\text { Resuscitation before admission to } \\
\text { hospital }\end{array}$ & 20 & 16 \\
Coronary care units & 6 & 5 \\
$\begin{array}{l}\text { Treatment with beta blockers after } \\
\text { infarction }\end{array}$ & 3 & 2 \\
Coronary surgery & $7\left(23^{\star}\right)$ & $5\left(18^{\star}\right)$ \\
Treatment of hypertension & 15 & 12 \\
\hline Total & 51 & 40 \\
\hline
\end{tabular}

${ }^{\star}$ Upper estimate.

\section{RESUSCITATION AND CARE BEFORE ADMISSION TO HOSPITAL}

Resuscitation before admission to hospital might potentially have a large impact on mortality as two thirds of deaths from coronary heart disease in New Zealand occur outside hospital. ${ }^{8}$ In Auckland in 1974 only one life support unit operated; by 1981 there were six units. ${ }^{9}$ In 1981 there were 24 long term survivors (aged 42-76) who had been resuscitated successfully after either ventricular fibrillation or cardiac arrest in the Auckland region. ${ }^{10}$ The equivalent number of survivors in 1974 is not known. If it is assumed that there were four long term survivors aged less than 70 for each life support unit the net gain in survivors in 1981 compared with 1974 attributable to resuscitation and care before admission to hospital was 20 . This is $16 \%$ of the total observed decline in mortality from coronary heart disease in 1981 in Auckland among people aged under 70 years.

\section{CORONARY CARE UNITS}

The major contribution of coronary care units to the declining mortality is in the detection and treatment of potentially fatal arryhthmias, specifically ventricular fibrillation, after myocardial infarction. ${ }^{11}$ In 1974,525 patients aged under 70 were admitted to coronary care units in Auckland with a definite myocardial infarction ${ }^{12}$; in 1981 there were 715 such admissions. ${ }^{13}$ In 1981 the incidence of ventricular fibrillation in one Auckland coronary care unit in patients with definite myocardial infarction was $5 \%{ }^{14} ; 90 \%$ of these patients were resuscitated successfully. Mortality one year after resuscitation is about $30 \% .{ }^{15}$ If it is assumed that these rates were the same in 1974 the net contribution of coronary care units in Auckland to improving the chance of survival after myocardial infarction has been six extra survivors $((715 \times$ $0.05 \times 0.9 \times 0.7)-(525 \times 0.05 \times 0.9 \times 0.7))$; this is $5 \%$ of the total observed decline in mortality from coronary heart disease in 1981 in Auckland among people aged less than 70 .

\section{TREATMENT WITH BETA BLOCKERS AFTER MYOCARDIAL INFARCTION}

Randomised controlled trials of treatment with beta blockers have shown a $25 \%$ reduction in mortality in the first year after discharge from hospital after definite myocardial infarction in people aged less than $70 .^{16}$ In Auckland between 1974 and 1981 the percentage use of beta blockers before a myocardial infarction for people aged under 70 doubled from $15 \%$ to $30 \% .{ }^{13}$ The percentage of patients using beta blockers after discharge from one Auckland hospital in 1981 after myocardial infarction was $24 \%$ (D N Sharpe, unpublished data). I have assumed that in 1974 the comparable percentage for all patients in Auckland was $15 \%$ and in $1981,30 \%$.

Total mortality in hospitals after myocardial infarction in 1981 was $10 \%{ }^{14}$; the corresponding mortality in 1974 was $16 \% .{ }^{17}$ If treatment with beta blockers reduces the mortality one year after discharge by $2 \cdot 5 \%$ from $10 \%{ }^{16}$ the net increase in survivors in 1981 attributable to the increased use of beta blockers is about three people $((715 \times 0.9 \times 0.3 \times 0.025)-(525 \times 0.84 \times$ $0.715 \times 0.025)$ ). This is $2 \%$ of the total observed decline in mortality from coronary heart disease in Auckland in 1981 among people under 70 years.

\section{CORONARY SURGERY}

Coronary artery bypass surgery has been performed in New Zealand since 1969 , and, as elsewhere, its main indication is for the relief of symptoms. Operations for left main stem and triple vessel disease have been shown in randomised controlled trials to improve survival, ${ }^{18}$ and in some descriptive analytical studies better chances of survival were found among patients considered to be at high risk who received operations. ${ }^{19}$ In Auckland 89 patients (in both the public and private sectors) underwent coronary bypass grafting (without other cardiac operations such as ventricular aneurysmectomy) in 1974 , as did 184 patients in 1981 . In $1974,47(53 \%)$ of the 89 operations and in $1981,138(75 \%)$ of the 184 operations were for patients with a "myocardial score" of 10 or more, which includes all patients with left main stem and triple vessel disease. ${ }^{20}$

In Auckland the contribution of surgery to the decline in mortality is difficult to assess as surgical patients are judged by their clinicians to be more symptomatic and have more severe disease than patients studied in several of the reported randomised trials. Consequently, a range of estimates was prepared of the benefit that might have been experienced by patients from Auckland as a result of surgery. Allowance was made for a continuing benefit of surgery for up to six years after operation.

The clinical course of patients with severe angina is difficult to determine but is a prerequisite for comparison of survival of patients who have received operations in the absence of appropriate randomised controlled trials. The use of historical controls is always hazardous because of possible changes in the clinical course of the disease between the time the observations were made on controls and cases and serious unrecognised biases due to different therapeutic and environmental influences at different times.

A study of patients from the Cleveland Clinic with functional class III and IV coronary heart disease in the early $1960 \mathrm{~s},{ }^{21}$ who Auckland clinicians judge to be similar to their patients, suggests that they would experience a natural annual mortality of about $12 \%$. This estimate, however, comes from the United States before the decline in coronary heart disease and newer modalities of medical management became available, modalities which in the judgment of many have had an impact on the clinical course of this disease. ${ }^{18}$ Several other studies have considered the clinical course of patients with severe coronary artery disease and an abnormal exercise test and have found high mortalities. ${ }^{22-24}$

If the Auckland patients with myocardial scores of 10 or more who had coronary artery bypass grafting were indeed similarly at risk to those patients from the United States in the 1960s, and their assumed annual mortality in the absence of operations was $12 \%$ each year, then an upper limit of the contribution of coronary artery bypass grafting to the decline would be $30 \%$. As Rutherford noted, however, the annual mortality in the more recent Coronary Artery Surgery Study of medically treated patients with severe triple vessel disease was $2 \cdot 1 \%$ compared with $11 \cdot 4 \%$ in the $1960 \mathrm{~s} .{ }^{25}$ If the Auckland patients participated in this change in clinical course and thus their annual mortality in the absence of surgery was closer to $7 \%$ each year (instead of $12 \%$ ) the contribution of coronary artery bypass grafting to the decline in mortality falls to $18 \%$.

The lowest predictions of effect come from the European Coronary Surgery Study. ${ }^{26}$ The European study has the advantage of being a randomised trial, but it was limited to patients with stable chronic angina who did not require operations to relieve symptoms. If it is assumed that the Auckland patients with myocardial scores of 10 or more experienced only the same benefit as all patients in the European study the net gain from surgery in 1981 compared with 1974 would be seven deaths averted. This would account for $5 \%$ of the observed decline in mortality from coronary heart disease in Auckland.

\section{TREATMENT OF HYPERTENSION}

It is difficult to assess the contribution of improvements in the effectiveness of the treatment of hypertension in the community to the decline in mortality from coronary heart disease. In 1981 about $20 \%$ of the Auckland population aged 35-64 years were hypertensive, and 55\% of these people were receiving pharmacological treatment. ${ }^{27}$ The state in Auckland in 1974 is unknown. In two studies in other parts of New Zealand in the early 1970s, however, the prevalence of hypertension was similar to that observed in 1981 , but only $30 \%$ of hypertensive subjects received treatment. ${ }^{28}{ }^{29}$ Thus in Auckland there were an estimated 15000 extra hypertensive patients being treated in 1981 compared with 1974. The Australian National Blood Pressure Study showed that for every 1000 hypertensive patients receiving 
treatment for a year deaths from coronary heart disease were reduced by one. ${ }^{30}$ In Auckland among those aged 35-69 the increase in treatment of hypertension in 1981 compared with 1974 would account for 15 deaths averted, or $12 \%$ of the decline in mortality from coronary heart disease.

\section{Discussion}

These data suggest that medical management was responsible for about $40 \%$ of the observed decline in coronary heart disease that occurred in Auckland in 1981 (table). The major contributions came from resuscitation before admission to hospital $(16 \%)$ and the improved control of hypertension $(12 \%)$, with smaller contributions from coronary surgery, coronary units, and the use of beta blockers after myocardial infarction. It was not possible to assess the contribution of other aspects of medical care, such as stopping smoking and early mobilisation after myocardial infarction, though their contribution is probably small.

These figures are only estimates. The contribution of resuscitation before admission to hospital may have been underestimated as it is assumed that the original life support unit was operating in 1974 as efficiently as the units in 1981. The contribution of improvements in the control of hypertension was difficult to estimate, and the link between control of hypertension and reduction in mortality from coronary heart disease remains unclear. As the quality of treatment of hypertension in Auckland may not have been as effective as that attained in the Australian trial the present estimate is optimistic. The assessment of the contribution of coronary surgery is the most contentious. The first estimate considers the possibility that most surgical patients experience a substantially improved chance of survival. If in fact the benefits in survival after surgery are small compared with the survival of patients who are adequately treated medically then the contribution of surgery to the overall decline would be small.

The Auckland estimate of the contribution of medical and surgical management is consistent with a recent estimate from the United States.' From various data, roughly $40 \%$ of the decline in mortality from coronary heart disease in the United States between 1968 and 1978 was attributed to medical interventions, with the major contributions coming from coronary care units, medical treatment of clinical coronary disease, and the treatment of hypertension. Goldman and Cook noted a contribution from the use of beta blockers in the treatment of angina. ${ }^{1}$ No attempt was made to study this in the Auckland assessment as over $80 \%$ of beta blockers prescribed by general practitioners in New Zealand are for the treatment of hypertension (Intercontinental Medical Statistics (New Zealand) Ltd, unpublished data).

Changes in the national diet and smoking habits that began in the early 1960s may well have had an important role in the initiation of the decline in mortality from coronary heart disease that began in New Zealand in $1968 . .^{31}$ Mortality began to decline before coronary care units, resuscitation before admission to hospital, and coronary surgery came into use. From 1968 to 1981 medical interventions were responsible for about $25 \%$ of the total observed decline in mortality from coronary heart disease in Auckland in 1981 among people aged less than 70 . Over this longer period the major contributions came from resuscitation before admission to hospital and coronary care units (10\% each); smaller contributions came from coronary surgery and the use of beta blockers.

These results suggest that resuscitation before admission to hospital could continue to make an important contribution to reduction in mortality, as could improvements in the community effectiveness of the treatment of hypertension. The other medical interventions are unlikely to have much impact on mortality in the future. In Auckland $95 \%$ of patients with myocardial infarction are treated in hospital, over $90 \%$ of them receiving initial management in coronary care units. ${ }^{13}$ Was the mortality one year after resuscitation in coronary care units to decrease to $15 \%$ this would avert only one more death from coronary heart disease in Auckland each year. Increased use of beta blockers after myocardial infarction would probably add little: if the percentage use in Auckland in 1981 had been $70 \%$ (instead of $30 \%$ ) there would have been an extra six survivors. As Rose reasoned, the use of beta blockers will not make a noticeable contribution to national mortality trends..$^{32}$ Likewise, given the already low mortality after infarction, the newer secondary preventive measures, such as coronary angioplasty and thrombolytic treatment, will not substantially influence future mortalities. Finally, given the continuing developments in medical treatment, the contribution of coronary artery surgery to future mortality trends will probably be small.

Most of the decline in mortality from coronary heart disease in Auckland during the period 1974-81 is attributable to factors other than specific medical interventions. There have been recent improvements in the national diet and a reduction in the consumption of tobacco, and these factors, or others not identified or unforseen at present, seem to be of major importance in New Zealand as in the United States.'

This research was supported by the Medical Research Council and the National Heart Foundation of New Zealand. I thank Sir Brian Barratt-Boyes and $\operatorname{Dr} \mathrm{R} M \mathrm{~L}$ Whitlock for providing the coronary surgery data; the many colleagues who commented on earlier drafts; and Melanie Scott, who prepared the manuscript.

\section{References}

1 Goldman L, Cook EF. The decline in ischemic heart disease mortality rates. Ann Int Med 1984;101:825-36.

2 Gillum RF, Folsom MR, Blackburn H. Decline in coronary heart disease mortality. Am f Med 1984;76:1055-65.

3 Kannel WB, Thom TJ. Declining cardiovascular mortality. Circulation 1984;70:331-6.

4 Feinleib M, Rifkind BM. Changing patterns of cardiovascular disease mortality in the United States. Isr $\mathcal{J}$ Med Sci 1982;18:1098-105.

5 Stern MP. The recent decline in ischemic heart disease mortality. Ann Int Med 1979;91:630-40.

6 Beaglehole R, Jackson RT. Coronary heart disease mortality, morbidity and risk factor trends in New Zealand. Cardiology 1985;72:29-34.

7 Beaglehole R, Bonita R, Jackson R, Stewart A, Sharpe N, Fraser GE. Trends in coronary heart disease event rates in New Zealand. Am 7 Epidiol 1984;120:225-35.

8 Foster FH, Hay DR. Mortality patterns in acute coronary heart disease in New Zealand. NZ Med f 1976;83:39-43.

9 Norris RM. Myocardial infarction: emergency management. Patient Management 1982;11:53-61.

10 Agnew TM, Lauder IM, et al. Sudden cardiac death: results of resuscitation begun outside hospital. NZ Med f 1983;96:465-7

11 Goldman L, Cook F, Hashimoto B, et al. Evidence that hospital care for acute myocardial infarction has not contributed to the decline in coronary mortality between 1973-1974 and 1978 1979. Circulation 1982;65:936-42.

12 Fraser GE. Definite myocardial infarction in Auckland. Aust NZ F Med 1978;8:479-90.

13 Beaglehole R, Stewart AW, Bonita R, Jackson RT, Sharpe DN. Myocardial infarction and sudden death in Auckland. NZ Med $\mathcal{F}$ 1984;97:715-8

14 Sharpe DN, Ruygrok P, Millener N. An evaluation of the role of the coronary care unit at Auckland Hospital. The Evaluation Papers 1983;12:1-7.

15 Conley MJ, McNeer JF, Lee KL, et al. Cardiac arrest complicating acute myocardial infarction predictability and prognosis. Am $\mathcal{J}$ Cardiol 1977;39:7-12.

16 Barber NS, Lewis JA. Confidence in results of beta-blocker post infarction trials. Br Med $\mathcal{f}$ 1982;285:1749-50.

17 Williams B. Admissions to a coronary-care unit over the past seven years (1973-9). NZ Med $\mathcal{F}$ 1981;93:158-60

18 Braunwald E. Effects of coronary artery bypass grafting on survival. N Engl f Med 1983;309: $1181-4$

19 Heller RF, Leeder SR. The place of coronary artery bypass surgery: an appraisal. Med $\mathcal{F}$ Aust 1985;143:70-2.

20 Brandt PWT, Partridge JB, Wattie WJ. Coronary arteriography: method of presentation of the arteriogram report and a scoring system. Clin Radiol 1977;28:361-5.

21 Webster JS, Moberg C, Rincon G. Natural history of severe proximal coronary artery disease as documented by coronary cineangiography. Am J Cardiol 1974;33:195-200.

22 Ellestad MH, Wan MKC. Predictive implications of stress testing. Follow-up of 2700 subjects after maximum treadmill stress testing. Circulation 1975;51:363-9.

$23 \mathrm{McNeer} \mathrm{JF}$, Margolis JR, Lee KL, et al. The role of the exercise test in the evaluation of patients for ischemic heart disease. Circulation 1978;57:64-70.

24 Dagenais GR, Rouleau JR, Christen A, et al. Survival of patients with a strongly positive exercise electrocardiogram. Circulation 1982;65:452-6.

25 Rutherford JD. Coronary artery surgery, 1984. NZ Med f 1984;97:813-6.

26 European Coronary Surgery Study Group. Long term results of prospective randomised study of coronary artery bypass surgery in stable angina pectoris. Lancet 1982;ii:1173-80.

27 Jackson RT, Beaglehole R, Stewart AW. Blood pressure levels and the treatment of hypertension in Auckland 1982. NZ Med f 1983;95:873-6.

28 Christmas BW. Blood pressure levels of an urban adult New Zealand population. Napier, 1973. NZ Med J 1977;86:369-74.

29 Simpson FO, Waal-Manning HJ, Bolli P, Spears GFS. The Milton Survey: 2. Blood pressure and heart rate. NZ Med f 1978;88:1-4.

30 Australian National Blood Pressure Study Management Committee. Australian therapeutic trial in mild hypertension. Lancet 1980;i:1261-7.

31 Beaglehole R, Hay DR, Foster FH, Sharpe DN. Trends in coronary heart disease mortality and associated risk factors in New Zealand. NZ Med f 1981;93:371-5.

32 Rose G. Prophylaxis with $\beta$-blockers and the community. Br 7 Clin Pharmacol 1982;14:45-48S.

(Accepted 28 August 1985) 